\title{
PARÂMETROS ATMOSFÉRICOS E DA CULTURA UTILIZADOS NO CÁLCULO DO ÍNDICE DE ESTRESSE HÍDRICO DA CULTURA DO ALGODÃO
}

\author{
Silvia Oliveira Dayube ${ }^{1}$ \\ Mariana Lima de Jesus ${ }^{2}$ \\ Sérgio Batista de Assis Viana ${ }^{3}$
}

Resumo: O monitoramento da planta destaca-se como o método ideal de manejo de irrigação, Alguns modelos de indicadores do estresse das culturas foram desenvolvidos, entre os quais se encontra o Índice de Estresse Hídrico da Cultura (IEHC, ou CWSI - Crop Water Stress Index) proposto por Idso et al. (1981), que correlaciona a diferença de temperatura da folha e do ar (Tc-Ta) com o déficit de pressão do vapor d'água (DPV). Desta forma, objetivou-se analisar os parâmetros atmosféricos (Ta, e umidade relativa do ar) e da cultura (TC), medidos com um termômetro infravermelho, que são utilizados para calcular o CWSI do algodoeiro irrigado. Plantas em condições normais de transpiração apresentam valores de Ta superiores a Tc. Altas temperaturas associadas a baixa disponibilidade hídrica, resulta em temperatura foliar acima do ideal. O CWSI do algodoeiro foi classificado como favorável na maioria dos dias avaliados. O método pode ser empregado no monitoramento da irrigação.

Palavras-chave: Termometria infravermelha; Monitoramento via planta; Temperatura do ar.

\footnotetext{
${ }^{1}$ Engenheira Agrônoma/Universidade do Estado da Bahia, Brasil. E-mail: sildayube@hotmail.com.

2 Mestre/Universidade Federal do Espírito Santo, Brasil. E-mail: marianaldejesus@gmail.com.

${ }^{3}$ Professor/Universidade do Estado da Bahia, Brasil. E-mail: sviana@uneb.br.
} 